Article

\title{
Sustainable Recovery of Architectural Heritage: The Experience of a Worksite School in San Salvador
}

\author{
Silvia Santini ${ }^{1, *(\mathbb{D}}$, Vittoria Borghese ${ }^{1}$, Mario Micheli ${ }^{2}$ and Erick Orellana Paz ${ }^{3}$ \\ 1 Department of Architecture, Roma Tre University, 00153 Rome, Italy; vittoria.borghese@uniroma3.it \\ 2 Department of Humanities, Roma Tre University, 00146 Rome, Italy; mario.micheli@uniroma3.it \\ 3 Ministerio de Cultura de El Salvador, San Salvador CP-1101, El Salvador; eorellana@cultura.glob.cv \\ * Correspondence: silvia.santini@uniroma3.it
}

check for updates

Citation: Santini, S.; Borghese, V.; Micheli, M.; Orellana Paz, E. Sustainable Recovery of Architectural Heritage: The Experience of a Worksite School in San Salvador. Sustainability 2022, 14, 608. https:// doi.org/10.3390/su14020608

Academic Editor: Tan Yigitcanlar

Received: 10 December 2021

Accepted: 3 January 2022

Published: 6 January 2022

Publisher's Note: MDPI stays neutral with regard to jurisdictional claims in published maps and institutional affiliations.

Copyright: (c) 2022 by the authors. Licensee MDPI, Basel, Switzerland. This article is an open access article distributed under the terms and conditions of the Creative Commons Attribution (CC BY) license (https:// creativecommons.org/licenses/by/ $4.0 /)$.

\begin{abstract}
This paper presents the experience of both interdisciplinary and sustainable implementation of an educational construction site for the recovery of the architectural heritage in Central America. Rey Prendes House is representative of one hundred and forty-five houses made of wood, stamped steel sheet, and deployé that are located in the historical center of San Salvador. Its origin is linked to historical events, such as the strong migration of foreigners to El Salvador in the late nineteenth and early twentieth century, the presidential decrees that encouraged the reconstruction of the city with anti-seismic materials as a result of the earthquakes of 1873 and 1917. More recently, since 2017, Rey Prendes House has been included in the project funded by the Italian Agency for Development Cooperation. In this paper, the phases of the survey are documented with both materials and degradation analyses, the new design construction with BIM technology for the organization of the educational construction site, the creation of offices and laboratories for restoration and treatments of timber and metal details. Moreover, the study provides a contextual framework with the aim of describing the policies and the projects implemented, highlighting the adopted strategies, the results achieved, and outlining the path followed towards the design solutions for sustainable rehabilitation relating to future use.
\end{abstract}

Keywords: heritage; timber; educational construction site; HBIM; structure analysis; restoration; San Salvador; lamina deployé; lamina troquelada; CHSS

\section{Introduction}

The Architectural Heritage represents a fundamental global resource and a sign of the national cultural background.

It is precisely for these reasons that, in recent times, the organization of participatory architecture, in which the involvement and awareness are useful resources to start a social change, means introducing the theme of a collective work for the preservation of the ancient and cultural heritage. Becoming aware of the importance and complexity of their heritage helps citizens to take part in the long process of restoration, understanding how this procedure works, and how significant the maintenance of the culture is.

In general, buildings suffer from alteration over the years, due to use, location, external actions, degradation of materials, construction defects, and the competence of the workforce. Only where programmed and continuous maintenance is practiced are these negative effects very limited. Regular maintenance requires interdisciplinary work where knowledge, skills and experience of architects, structural engineers, historians, archaeologists, and chemicals merge.

Unluckily, in several situations, this work is more complicated than in others. As a matter of fact, in countries affected by seismic phenomena, as El Salvador is, a more complex operation of restoration must be carried out.

Usually, historic buildings suffer from a lack of diagnostic and maintenance controls and are frequently subject to the criterion of economic convenience. Unfortunately, when 
the financial contribution is insufficient, it is easiest to demolish and rebuild severely damaged structures. The alternative between rebuilding or repairing as-it-was is an open issue that reappears whenever an event brings out the relationship between safety and conservation. During the restoration project on a historical construction, the structural safety target must be understood with a different meaning compared to that one for new structures, especially in presence of seismic actions.

The maintenance and preservation of ancient buildings need a balance between the structural safety requirements and respect for their architectural and cultural value, especially in those countries exposed to a relevant seismic risk.

The history of structures, related to seismic events, highlights the importance of construction methods and of the execution of the details to guarantee the expected 'safety'. In many cases, the works needed to improve safety would be so invasive that they could compromise the historical asset. On the other hand, during an earthquake, insufficient seismic protection would make the collapse of buildings possible, causing victims, cultural and economic losses, as well as social problems. Quoting William Durant with his "civilization exists by geological consent, subject to change without notice", the foundation Programa Salvadoreño de Investigación Sobre Desarrollo y Medio Ambiente explained how the history of El Salvador was strongly marked by recurrent earthquakes, because of its position in the so-called Fire Ring (a portion of territory between the Pacific Ocean and the American West Coast) [1].

In the 20th century, El Salvador suffered up to 13 earthquakes of strong intensity. Among them, one occurred in October 1986, with 1500 victims, and the two events at the beginning of 2001, which affected the country violently, causing more than 1200 victims (Figure 1) [2].

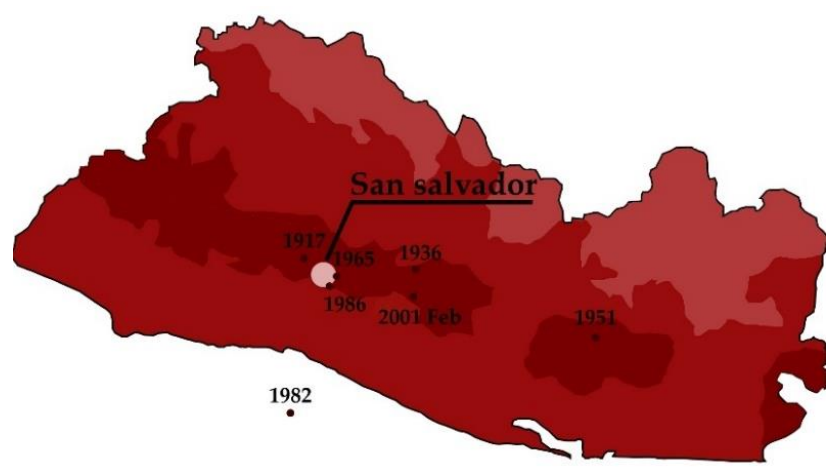

(a)

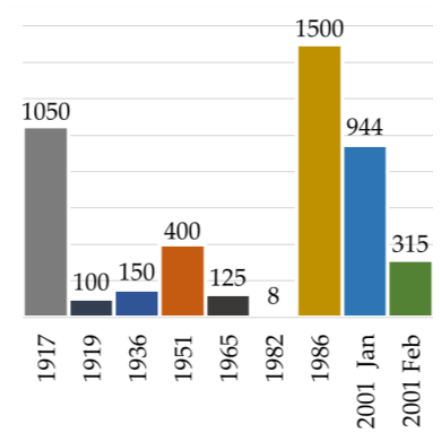

(b)

Figure 1. (a) Earthquakes identified from the SNET for epicenter and area of influence (from the most affected in dark red) in El Salvador during the XX century; (b) Number of deaths of each one.

In August 2012, August 2014, October 2014, and more recently in July 2019, the earth shook again. Geographically the territory is characterized by an imposing volcanic alignment and a tropical climatic situation with abundant rains and hurricanes [3].

The question of restoration is serious and requires full awareness of the role of all professionals involved. For this reason, the creation of "workshop-schools" allows field training capable of promoting an awareness culture and experimentation in restoration techniques, to organize an educational construction site both for students and for adults included in a social rehabilitation program.

To face such a complex challenge, an exemplar case study was selected as representative of a traditional construction technique of the old town of San Salvador.

In fact, to deal with seismic risk, in San Salvador from 1873, a new method was used: wooden frame and laminas (metal sheets) as finishing [4]. This construction type became popular as an "imported and tropicalized" system that was mostly used at the beginning of the 20th century as innovative, with respect to the traditional adobe construction.

In 2017, the worksite school, through the restoration of the property of the Rey Prendes House, was started within the project of "Strengthening the Secretary of Culture of the Pres- 
idency of El Salvador through the enhancement of cultural heritage", financed by the Italian Agency for Cooperation for Development and directed by Roma Tre University (Figure 2).

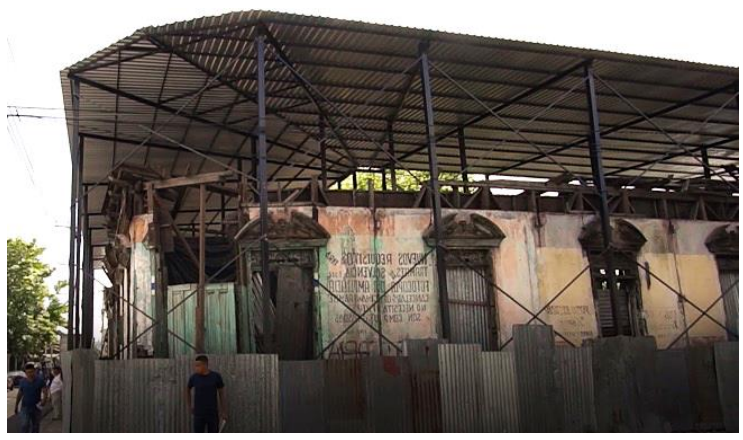

Figure 2. Construction site: temporary roof of Rey Prendes House.

This project has had the contribution of different actors: VMVDU (Vice Ministry Housing and Urban Development), INJUVE (National Institute of Youth) through the "Jóvenes con todo" program, the San Salvador Municipal Mayor's Office, and the Mayor's Office Municipal de Zacatecoluca as natural partners, CONAMYPE (National Commission of Micro and Small Business), the University of El Salvador, INSAFOCOOP (Instituto Salvadoran Cooperative Development), FUNDASAL (Fundación Salvadoreña de Desarrollo y Vivienda Mínima), the Roma Tre University, the INSAFORP (Salvadoran Institute of Professional Training) and the Ministry of Culture.

Undoubtedly, the current project for the House and its educational construction site arises as a perfect example in the so-called CHSS (Centro Histórico de San Salvador), becoming a cultural learning space, which brings together the CHSS students and gives life back to an edifice with historical value in the old town that still preserves its housing functions and that must be protected. The aim of this is to give a social and sustainable response to a structural dilemma, to create a social awareness of cultural heritage. To achieve the purpose of raising awareness that there are several modeling techniques that can be useful, as, for instance, Building Information Modeling.

Designing with BIM (Building Information Modeling) technology allows coordinating different professional figures, making modeling and construction element creation faster, avoiding, or considerably reducing, errors and mistakes (Figure 3) [5].

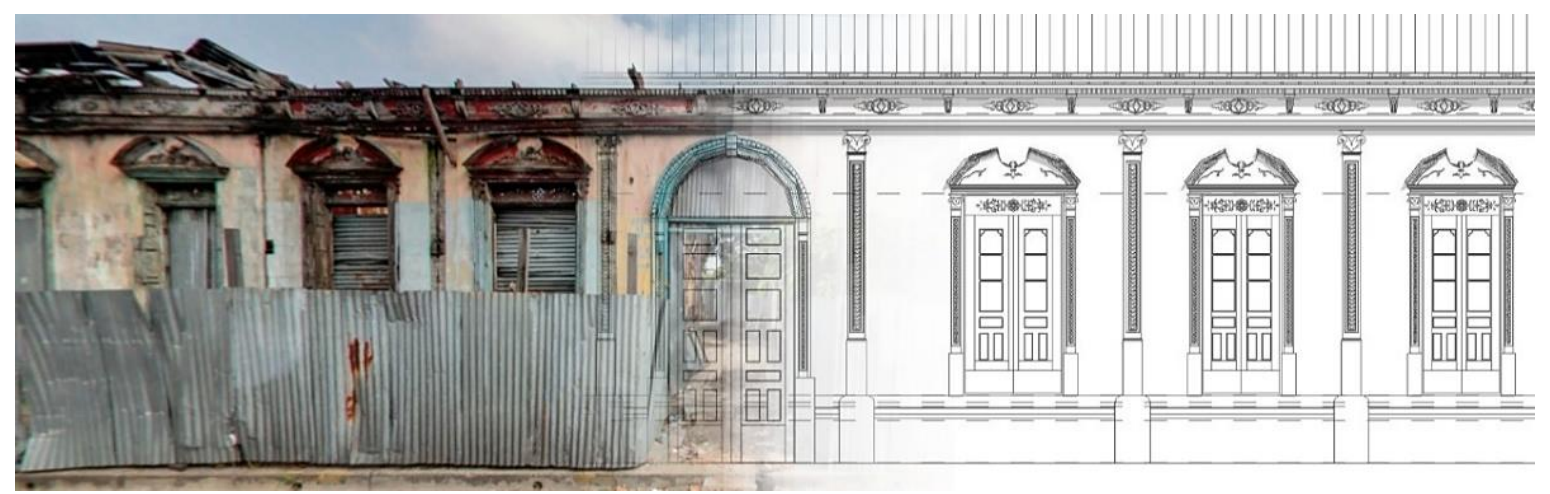

Figure 3. Transition between actual Rey Prendes House and the high accuracy of BIM modeling for the future project.

The noun 'Heritage', linked to the traditional and most well-known term 'Building Information Modeling', arises from the need to apply new design tools characterized by interoperability not only for new constructions but also as an innovative approach for existing structures. A simple connection is the witness of an innovative vision of architectural conservation and restoration, proposing a clear integration of all relief documents 
and papers, too often not accurate or reliable. On the other hand, HBIM supports designers and restorers, giving a high level of detail and accuracy that was difficult to get before, hence overcoming the problems (linked to complex and elaborate geometries and material deterioration).

To avoid these challenging problems related to graphic issues, the authors used parametric objects and customed libraries whose study and application on existing architecture began nearly a decade ago [6,7].

The HBIM modeling design, therefore, represents a summary of all documents and papers acquired, or available in general, about a specific building under study, its physicalchemical and mechanical properties, geometrical dimensions without neglecting future activities and related costs.

Currently, this relevant database is slightly structured and organized and it is the object of several doubts due to the lack of systems. Furthermore, the relative ease of importing and organizing graphic documents, $\mathrm{dwg}$ files, or point clouds is in contrast with the hardness of modeling existing structural elements. A serious lack, talking about this particular modeling typology, is described by the impossibility of representing and counting any material deterioration. Steel corrosion, capillary rising damp, moisture, wood cracking, and other phenomena cannot be realized, designed, or considered in any way, making an exception for photo or relief inclusion.

Pondering on its successful applications and uses that have revolutionized the conservation and restoration world, it can be noted how HBIM represents an important tool of innovation and technological development.

Starting from the simple three-dimensional modeling and the catalog of alreadyknown physical and mechanical properties with the aim of achieving a sort of virtual monument-document [8] and increasing the energy efficiency of existing edifices [9], the importance of the Heritage BIM digitalization is pervading, more and more preponderatingly, the view of architecture and the approach to historic buildings.

Differently from simplest modeling programs, which work with only three dimensions, allowing the creation of solids, curves, and lines, leaving out everything about parametric objects with additional information, the use of BIM technology provides for processing in seven dimensions, includes the study of sustainability, not only at an environmental level but with a multifaceted set of aspects [10].

For instance, according to the 2030 Agenda for Sustainable Development, an important part is about the so-called inclusive sustainability to «leave no one behind», a fundamental innovative concept that would hardly have been assimilated into this subject a few years ago [11].

For this project, only local wood or recycled materials of the existing collapsed building were used and the analysis of energy efficiency through the creation of preparatory compartment placements for possible future analysis has also been prepared.

The iter proposed allows managing the educational construction site in a smart way, reducing costs by limiting the overlap of processing and improving safety during the construction site.

The social life cycle assessment is as important as it is currently not so much investigated. For this reason, in this article, the authors emphasized the positive impact that the implementation of this project would have on society [12].

These analyses are useful to preserve the cultural identity and architectural and traditional values of El Salvador, taking into account the positive impact this type of project may have by making use of the involvement of the population and collaboration with local universities, which actively participate in the entire design and restoration process.

Precisely with the aim of emphasizing social and cultural values, it was decided to use the analyzed structure as a national coffee museum/factory, with the aim of restoring, not only the historical connection but also the social one. 
Creating a place of sociality, interaction, and culture where the ancient tradition of coffee, that has made this country famous, also improving its previous economic condition, is celebrated.

Until now, research done in this field, despite several years of studying, are mostly didactic, explicative, and usually focused on the process, step by step, of modeling creation.

The real innovative frontier of the application of this technology is based on actually finding out its extreme versatility and flexibility.

Most authors use HBIM as a support for integrated approaches for historical building adequacy and retrofit [13].

There is a large amount of data and information about this technology, which are provided by relief techniques, point clouds, and laser scanner files. Papers that address this topic debate about software and data interoperability, for instance, Cloud to BIM to FEM, or from laser scanner to BIM [14].

Starting from the research of M. Murphy (between 2009 and 2013), the HBIM became a database for mapping historical elements (from Vitruvius drawings to the 18th-century architectural pattern books) using parametric objects [15].

Other examples of historical buildings processed with HBIM technology are the Church of Saint Maria in Scaria d'Intelvi (Como) and Palazzo Soldi (Cremona) made by A. Georgopoulos et al. [8].

The evolution of this concept system concerns interoperability with other software to increase applications and benefits in various fields (energetic, structural, acoustic, and others). For instance, in 2015, the secondary school Mascagni (Melzo, Italy), constructed in the early Seventies, was totally re-built in a three-dimensional way to calculate the whole building performance [9]. As a matter of fact, a remarkable example is Notre-Dame de Paris that, after the 15 April 2019 fire, was totally rebuilt both as-it-was with BIM technology and adding hypothetical restoration by Andrew Milburn (Godwin Austen Johnson) using laser scanner technology (2020) [16].

Taking into account these general considerations about HBIM technology, its potential is based on several qualities and implementations, especially on restoration design, preservation of monuments, or construction site organization.

In the present paper, the construction site organization is one of the main points faced for the entire design project. As a matter of fact, the innovative and never-tested concept of a link between the HBIM technology and an educational construction site is a new and fresh topic for experimental modeling.

The HBIM simulation allows for several tests in different fields of application. For instance, the development of structures of the educational construction site could be made to coordinate workers and designers to place each historical element correctly. This represents the aim of the modeling process used to Rey Prendes House (Figure 4), a historical building in the old town of San Salvador.

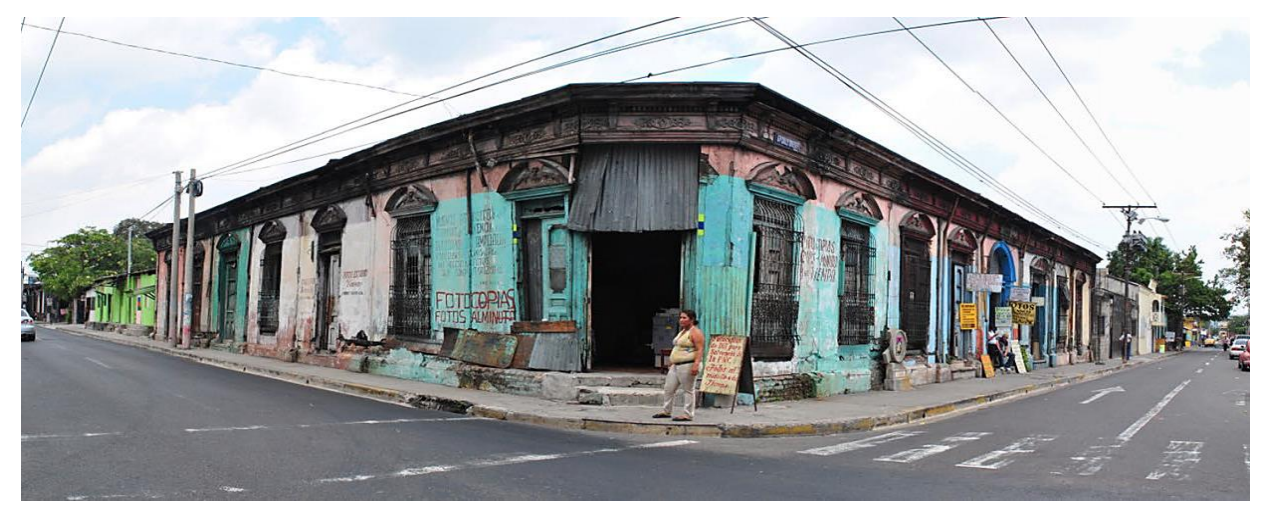

Figure 4. Rey Prendes House before the construction site set-up in 2010. 
So, focusing on these different aspects and steps of the building and modeling processes are relevant to creating a plan based on specific studies and methods.

Starting from the current disposition of the structural elements of the Rey Prendes House, the authors created in advance a model with SAP2000 [17] software to test several alternative options for the new project.

The restoration consised of demolition and reconstruction as-it-was reusing as much as possible the existing materials (as laminas and decorations) with the aim to preserve the cultural heritage of this city.

The SAP2000 data and results represent a preliminary work that provides the base modeling for information modeling with BIM technology and structural analysis for new projects.

The final aim is the setup and organization with Autodesk Revit [18] of an educational construction site with the time schedule and work phases for each processing level.

In order to organize this peculiar work on a historical building, the first step consisted of analyzing the site and its history and realizing an accurate digital twin of the edifice, due to UNI11337 (Figure 5). The digital twin consisted of an exact copy of the project to test the structure and count the necessary elements for reconstruction.

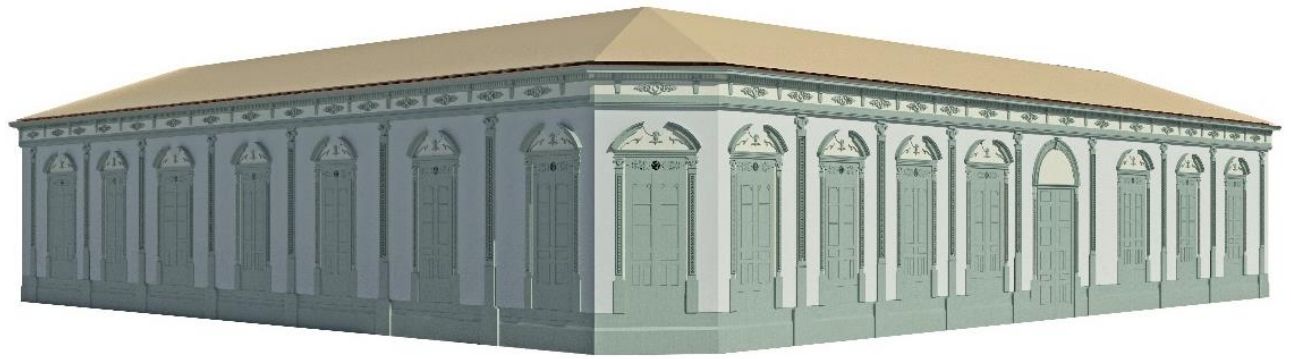

Figure 5. Digital twin of Rey Prendes House with BIM technology created with Autodesk Revit.

\section{Rey Prendes House}

Rey Prendes House is a historical building in San Salvador (capital city of El Salvador) of which neither the time of construction nor the architect is precisely known.

It is located in the old town of the city between the 10a Avenida Sur and the 6 Calle Ote, a few blocks away from Libertad Plaza and Palacio Nacional de San Salvador.

This edifice is one of the 145 historic buildings made of wood (madera) and sheet metal (làmina), sited on the so-called CHSS (Centro Historico de San Salvador) (Figure 6).

The intention was to rebuild the Rey Prendes House, trying to preserve as much as possible its original appearance.

During the expo known as "7 de Junio de 1917. Noche fatal", realized by the Museum MARTE and by the Academia Salvadoreña de la Historia, the Architect Ayansi Avendaño illustrated the benefits of these types of structures, made of light wood-framed construction and sheet metal coatings, placing emphasis on quick assembly and good seismic behavior, presenting them as the ideal candidates for post-seismic reconstruction.

Unfortunately, today this historical building is considered unsafe as a result of the roof collapse and the damage caused by the earthquakes (Figure 7).

Rey Prendes House is an L-shaped building composed of eight rooms and two entrance corridors, in the middle part of the wings, that brings the visitor to the central court. There is also another main entrance on the corner and the storage facility and the workshop area for professionals and students were placed on the opposite side.

A future project will also deal with the transformation of this area into a public space for study and lecture rooms (Figure 8). 


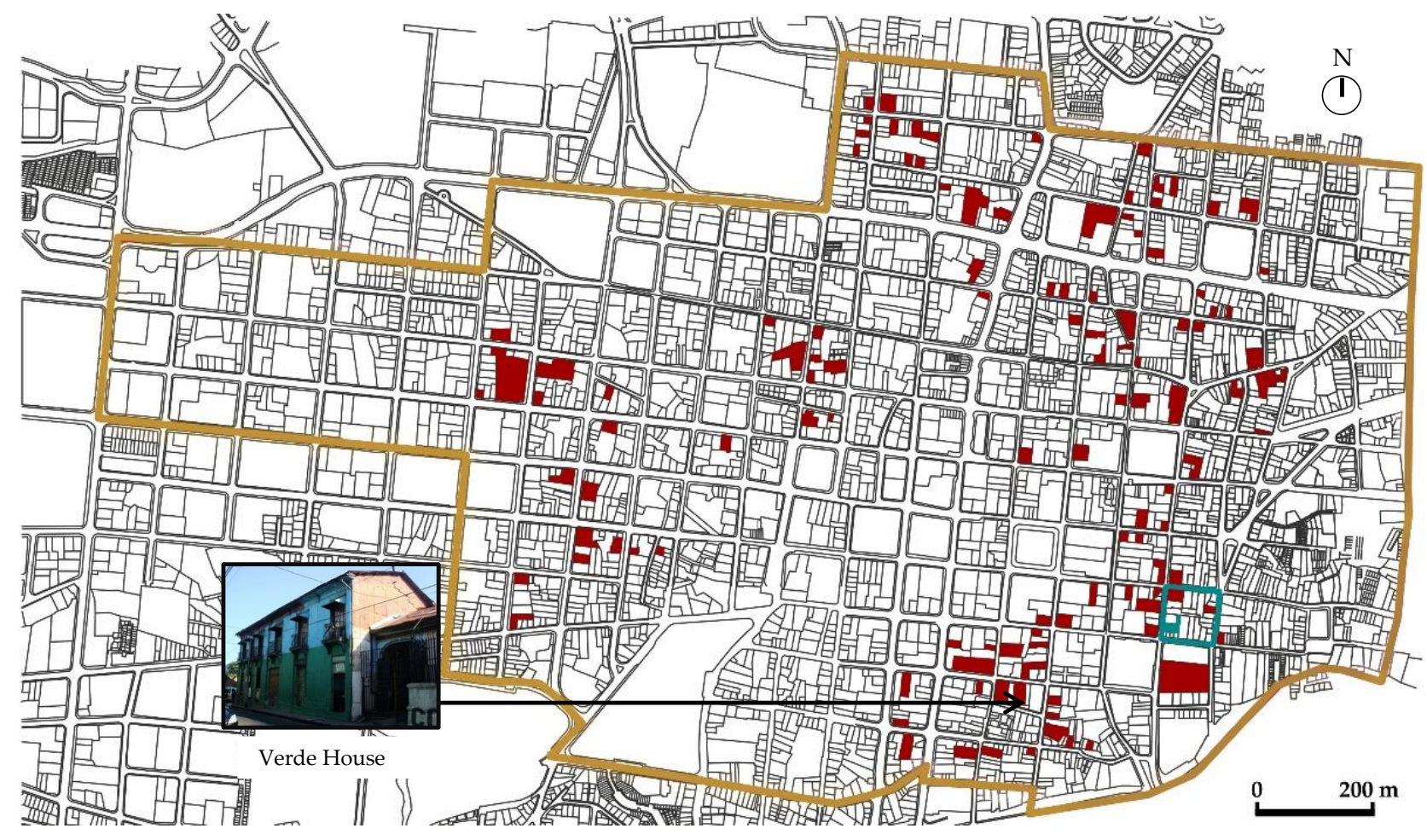

Figure 6. Map of CHSS of San Salvador (yellow line) with the location of all buildings made of wood and laminas in red and Rey Prendes House in blue, two blocks from Libertad Plaza and five from Palacio Nacional.

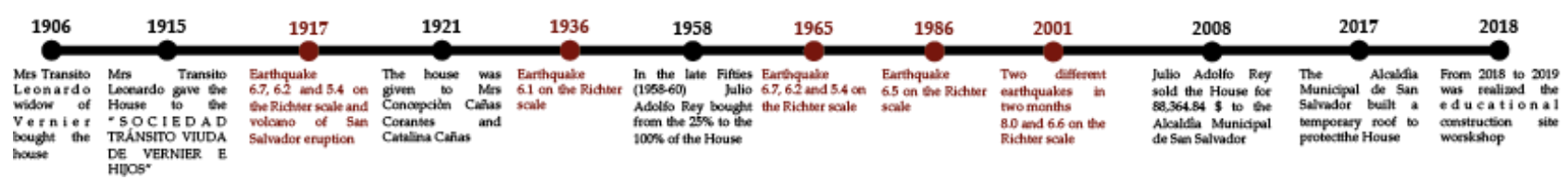

Figure 7. Timeline of Rey Prendes House during the last hundred years (within red the earthquake events and in black the history of the house).
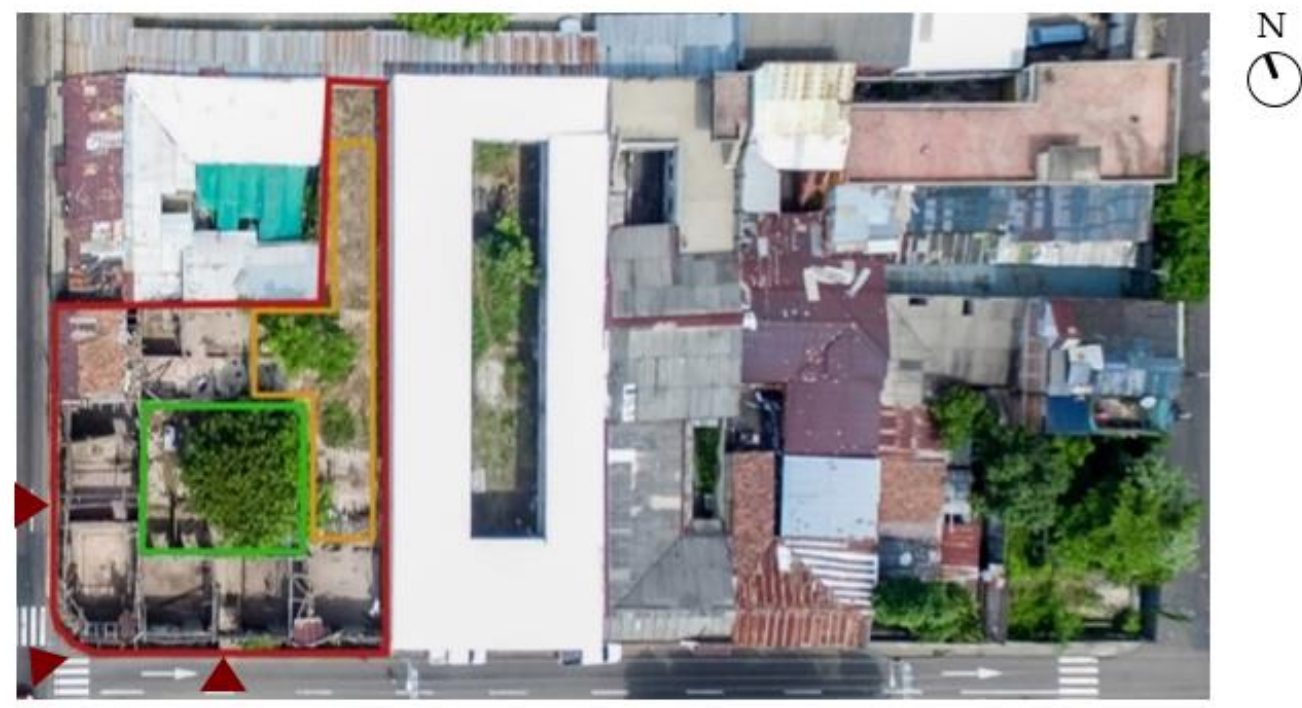

Figure 8. Plan of Rey Prendes House with the entrances in the block context captured by the drone with the borders underlined in red, the court in green, and the storage area in yellow. 
The structure is realized with wood wall framing, made with a technique similar to balloon frame, and several secondary frames with the function of supporting coating materials. These are divided into two different typologies: while outside, lamina deployé, made of sheet metal (used as reinforcement), and concrete is used. On the other hand, inside there is the lamina troquelada, useful for its dry assembly and decorations in relief (Figure 9).

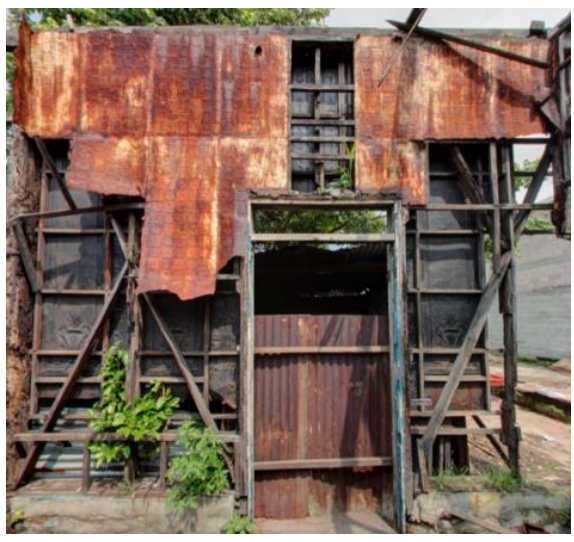

(a)

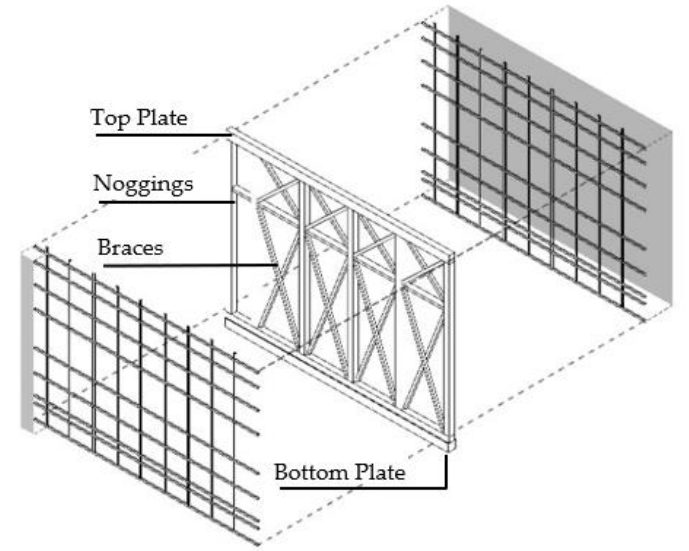

(b)

Figure 9. (a) Damaged laminas allow exploring the internal structure made of balloon frame; (b) Structure of the primary and secondary frames with laminas.

The supporting frame is composed of wall elements with horizontal noggings (bottom plate, middle nogging for increasing stiffener, and a top plate to complete), vertical studs as columns, and bracing members. The secondary structure, made of irregular grids of wooden elements, is different depending on the need for a special positioning of the coating plates.

At the base of the structure, there is a masonry curb and, below, a network of concrete beams that discharge loads in a linear way on the ground level.

A characterizing element is represented by the wooden trussed roof, made of a double frame of rafters and beams with three struts inside at various inclinations. The decorative finishing elements are built of painted wood with bright colors, typical of Central American architecture.

\section{Structural Project}

The objective of this section of the work is to provide a structural solution made entirely of local wood, starting with the analysis of the existing structure, and collecting data for the future project. The existing building, as already said, was made with a technology similar to the balloon frame, with pillars at a short distance, linked by braces (crosses of San Andrés). The balloon frame coating, which is usually made of wooden panels and plasterboard, in this case, was composed of decorated metal sheets.

The structure was fixed to the brick-built base with steel screws.

At the top, the structural elements were joined together with a continuous band around the slab, considered a rigid element in its own plane, aimed to withstand the horizontal actions caused by the wind or earthquake.

In this typical construction system, the redundancy of load transmission paths, due to the abundance of structural elements and bracing elements, is favorable in the case of seismic actions. This solution provides additional safety in case of earthquakes since a possible crisis of a load transmission path can be compensated by adjacent elements or bracings, unlike buildings made with large spans and fewer joints between elements.

Obviously, such an advantage is closely linked to the effective execution of the details. The construction floor is L-shaped, with a $25.00 \times 9.70 \mathrm{~m}$ wing approximately and the other $26.65 \times 10.00 \mathrm{~m}$. With regard to the materials, the species of local wood to be used are Copinol, Nispero, Volador, and Conacaste. 
In the laboratory of the Department of Structural Mechanics of the UCA, Universidad Centro American "José Simeón Cañas", a series of tests were carried out to determine the mechanical properties of these local woods, an occasion during which a collaboration agreement between PRiSMa (Proof testing and Research in Structures and Materials) of the Department of Architecture of the Roma Tre University and the UCA started. Entering the specifics, compression tests were carried out parallel with fiber direction and bending tests, according to the ASTM D143-14 (Figure 10, Table 1).

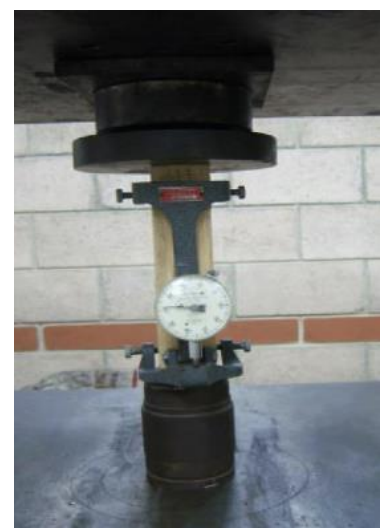

(a)

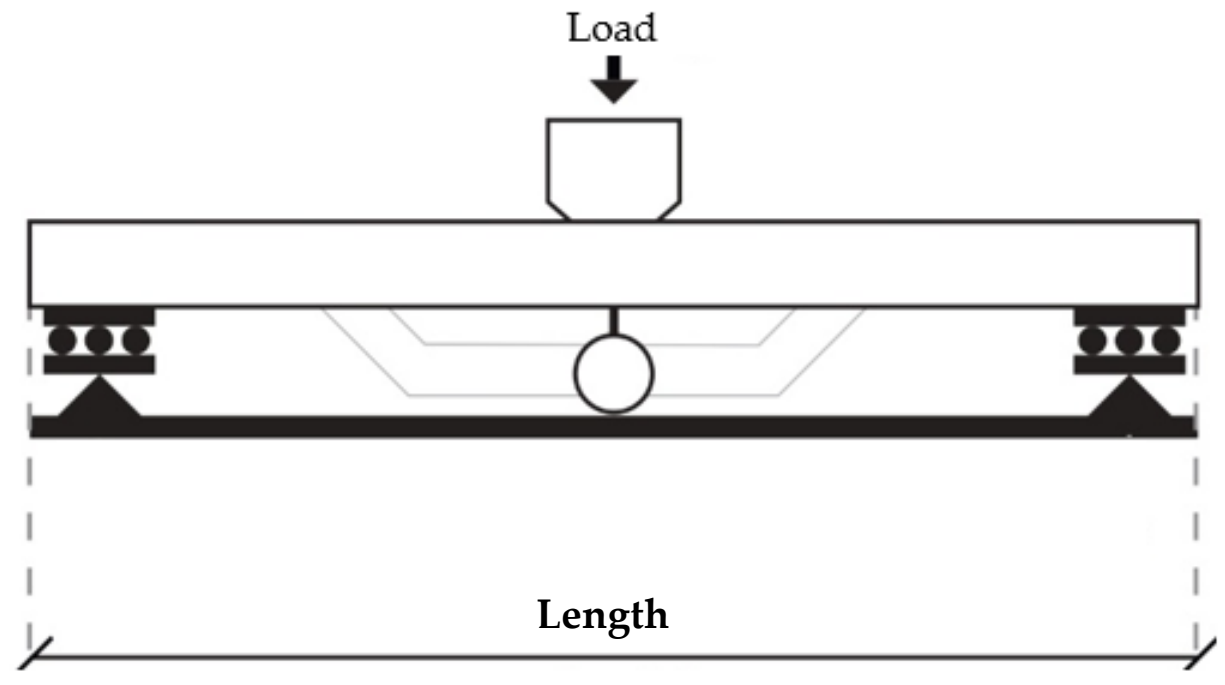

(b)

Figure 10. (a) Setup for compression test; (b) Bending test.

Table 1. Synthesis of experimental results (UCA).

\begin{tabular}{|c|c|c|c|c|c|c|c|}
\hline Test Type & Unit & Bàlsamo & $\begin{array}{l}\text { Cedar/ } \\
\text { Cedro }\end{array}$ & Conacaste & $\begin{array}{l}\text { Conipol/ } \\
\text { Courbaril }\end{array}$ & $\begin{array}{l}\text { Loquat/ } \\
\text { Nispero }\end{array}$ & Volador \\
\hline Shear stress & psi & 1800.00 & 1425.00 & 1034.00 & 2082.00 & 1694.00 & 1601.00 \\
\hline Average compression stress & psi & $10,885.00$ & 4238.00 & 3411.00 & $11,606.00$ & 9836.00 & 7350.00 \\
\hline Average Young modulus & ksi & 2209.00 & 1397.00 & 765.00 & 2266.00 & 2039.00 & 2000.00 \\
\hline Average moisture & $\mathrm{lb} / \mathrm{pie}^{3}$ & 58.52 & 31.38 & 31.97 & 57.83 & 65.33 & 49.46 \\
\hline Average density & $\mathrm{lb} / \mathrm{pie}^{3}$ & 53.84 & 27.96 & 28.70 & 53.24 & 62.36 & 45.17 \\
\hline Average moisture percentage & $\%$ & 8.7 & 12.4 & 11.5 & 8.6 & 5.6 & 9.5 \\
\hline Bending modulus & Psi & $24,358.00$ & 5991.00 & 7522.00 & $15,111.00$ & $18,491.00$ & 9056.00 \\
\hline Module of flexural elasticity & Ksi & 2382.00 & 804.00 & 936.00 & 1789.00 & 2134.00 & 1392.00 \\
\hline Tension stress & Psi & $22,500.00$ & $\mathrm{~b}$ & c & $13,400.00$ & $17,300.00$ & 6100.00 \\
\hline Tension stress modulus & Ksi & 2870.00 & $\mathrm{~b}$ & c & 2530.00 & 2190.00 & 1390.00 \\
\hline
\end{tabular}

a: test piece failed in a knot. b: no-representative result. c: not received results for this type of wood.

The vertical structures and the load-bearing elements of the roof were dimensioned by standardizing the geometry, where possible, to facilitate production and to make the realization faster. An intermediate floor was added, placed between the top of the walls and the ceiling braces, to improve the behavior of the set in the face of horizontal actions, such as seismic ones.

For the analysis design, reference was made to the Regulation for the structural "Safety of Constructions" of El Salvador, and more specifically, with regard to wind and earthquake actions to the regulation of the Ministry of Public Works of the Republic of El Salvador, "Technical standard for earthquake design" and "Technical standard for wind design".

For the structural tests on elements, reference was made to the "Testo Unico" in force in Italy and, consequently, to the European standard EN 1995-1-1: 2004 "Design of Timber Structures", as specific local references in this regard do not exist.

Unfortunately, in El Salvador, there is no provision for any type of wood quality control structural use on-site, not even on the amount of moisture admitted. 
As a result of these considerations, for the dimensioning of the structure, it was decided to use European certified wood, to be able to carry out all the controls, following the regulations in force in Italy and Europe.

The authors opted for the use of solid wood class D30 from the broadleaf family, compatible with the local wood already indicated.

Regarding the joints between elements, a class 8.8 steel with resistance ultimate tensile equivalent to $\mathrm{fu}=800 \mathrm{MPa}$ was chosen.

The actions and permanent loads were dimensioned according to the codes, considering the self-weight of the structural elements. On the other hand, for variable loads, which depend on the destination of use, taking into account that it is a single-story building, a roof practicable for maintenance only was considered.

About seismic action, having the data available related to a study of the soil carried out in 2012 and, considering the Regulation for "Structural Safety of Constructions" of El Salvador, the safety coefficients (such as acceleration, importance factor, soil type, and spectrum values) were adopted: $\mathrm{A}=0.40 \mathrm{~g}, \mathrm{I}=1.00$, Soil Type $\mathrm{S} 3, \mathrm{C}_{\mathrm{O}}=3.00, \mathrm{~T}_{\mathrm{O}}=0.60 \mathrm{~s}$.

Regarding the action of the wind, based on what is established by the Technical Standard For the Wind Design, the action $\mathrm{P}=\mathrm{C}_{\mathrm{p}}$ CZKP0 was considered with the following parameters: $\mathrm{P} 0=30 \mathrm{~kg} / \mathrm{m}^{2}$, Zone $\mathrm{B}: \mathrm{K}=1, \mathrm{CZ}=1, \mathrm{C}_{\mathrm{p}}=0.8$ for Windward Wall, $\mathrm{C}_{\mathrm{p}}=-0.5$ for Wall Leeward, $C_{p}=-0.87$ for Roof $\theta<30^{\circ}$.

Finally, in addition to seismic ones, the fundamental combinations of the ultimate limit state with variable $\mathrm{Q}$ prevalence and $\mathrm{V}$ wind were taken.

Defining the actions as just described, the structure was analyzed with the method of the finite elements, through the construction of a three-dimensional model using the SAP2000 software (Version 11).

This step allowed the new project construction with BIM technology; as a matter of fact, this helped to decide the final version of the new project.

In this preliminary analysis, frame elements were exclusively used to model columns, beams, bracings, and braces.

The intermediate floor and the trussed roof were examined separately, to verify the section of the joists, while the model considered its own action by assigning to the structures on which they impose a linear load proportional to the areas of influence.

In addition, it must be considered that the finishing elements of the intermediate slab and the roof can function as stiffening elements in the plane itself. This allows obtaining good overall performance of the structure against horizontal actions and efficient force transmission to the resistant vertical structure. For this reason, it was decided to introduce a link between the nodes of the roof elements. A bond that is commonly defined as a 'rigid plane'.

The static analysis took into account the permanent and variable loads and those of the wind action. Verifications of the stresses, including instability, were carried out considering a permanent type of cargo duration class, which provides for more than ten years, and a service class of type 2 , characterized by material moisture in equilibrium with the environment at a temperature of $20^{\circ} \mathrm{C}$ and relative humidity of the surrounding air that only exceed $85 \%$ for a few weeks of the year.

Consequently, considering the appropriate safety factors, the main elements were dimensioned as follows:

- $\quad$ Strut of the wooden truss $\mathrm{b}=64 \mathrm{~mm}, \mathrm{~h}=126$;

- $\quad$ Strut of the half angular truss $b=140 \mathrm{~mm}, \mathrm{~h}=200$;

- $\quad$ Strut of the half angular truss $b=140 \mathrm{~mm}, \mathrm{~h}=140$;

- $\quad$ Corner pillar $\mathrm{b}=140 \mathrm{~mm}, \mathrm{~h}=140$;

- $\quad$ Element of the cross of San Andrés most requested $b=64 \mathrm{~mm}, \mathrm{~h}=126 \mathrm{~mm}$.

Finally, the connection between elements by means of steel screws of class 8.8 was indicated in the relative detail plans. 
After this preliminary work, all data and information were collected and it was possible to build the digital twin required from guidelines (included in UNI 11337), to create the BIM modeling of the complex structure (Figure 11) and the architectonic details.

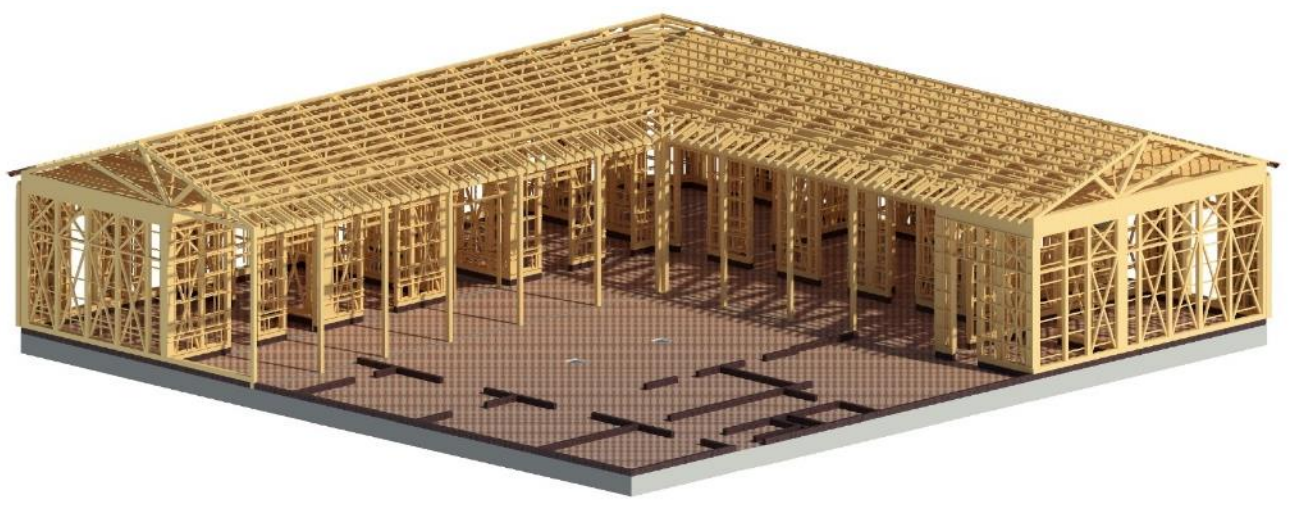

Figure 11. View of the entire structure created by BIM technology.

\section{HBIM Modeling}

Project Rey Prendes House involves a program for the building reconstruction of a severely damaged structure, with the intent of changing its function into a museum through a valorization process. The design purpose follows the existing historical shell but improves the structural performance.

The architectural and structural modeling is useful to give a detailed description of the informative project properties and finalize it to the design activity optimization and the organization of all necessary tests made through the use of innovative methodologies and specific software.

The project aim consisted of making a single model that could be read by other programs, to develop data project and unifying files, considering that useful documents for the model's construction are represented by project tables elaborated with AutoCAD [19] and photos or videos realized with drone aid.

The authors used Revit to realize the digital twin of the Rey Prendes House, starting by setting grids and levels to create common coordinates and landmarks.

The bearing structure, as already said, was made with a technique similar to the balloon frame construction, with short gap pillars and beams' short spans. The Revit model was set shaping a rigid and regular grid on the plan and placing a levels system that is useful for beam element placement (Figure 12).

\begin{tabular}{lccc}
\hline & Basis & Structure & Architecture \\
\hline Foundations & Grids & Walls & Finishing \\
\hline Elevation & Levels & Bottom plates & Laminas \\
& & Pilasters & Uprights \\
& & Noggings & Door \\
& & Braces & Plaster \\
& & Top plates & Plinth \\
\hline Trussed roof & & Trusses & Roof finishing \\
\hline
\end{tabular}

(a)

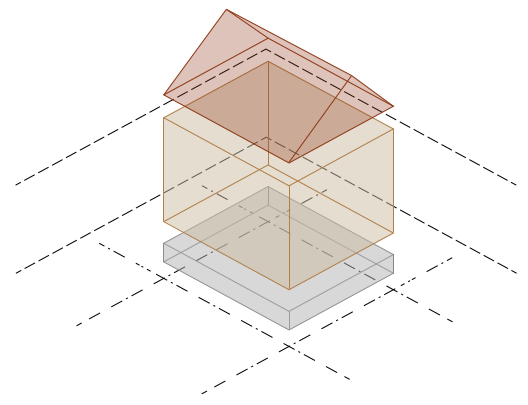

(b)

Figure 12. (a) Abacus of the elevation and foundation structure with the elements named; (b) concept for abacus comprehension of a small section of the Rey Prendes House.

Axis 1-6 through the abscissa and A-G for the $y$-axis were identified (Figure 13). After a secondary denser grid was placed to divide with accuracy pilasters that, as a result, in Revit, are named for their location. 


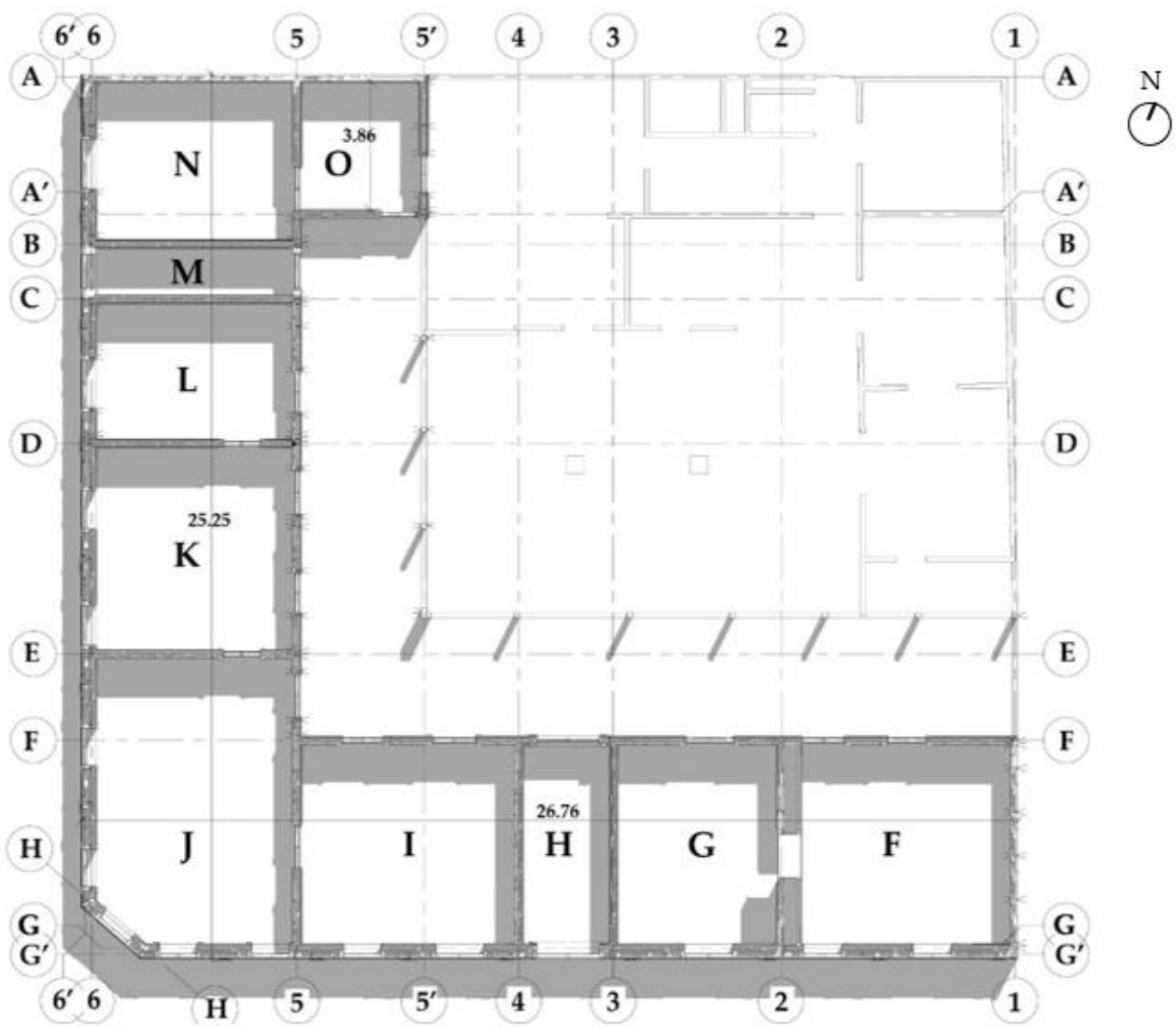

Figure 13. Plan of Rey Prendes House with grids built to generate elements' names to place them correctly during the educational construction site and compartments placement (named from $\mathrm{F}$ to $\mathrm{O}$ ) to allow LCA analysis.

Each vertical element is consequently found, following the type properties, thanks to marked positions that auto-name the elements with grid references $\mathrm{Y}, \mathrm{X}$ (ex. Pillar A-4.2).

Then, the authors proceeded to create structural elements starting with the foundation and continuing with the elevation elements. Structural elements are modeled by the structure window of Revit, paying attention to the fact that the property's "analytic model" was always on.

Thanks to this function it is guaranteed the interoperability with MidasGen [20], or with other programs like this one.

The future step could be the analysis of this new project without constructing another model, guaranteeing the perfect matching between structural tests and design choices. The "Analytic model" allows transforming a geometric element (structural beam, structural plaster, or structural wall) into a frame with an initial and terminal node or into a plate with four nodes ad at the edges.

Foundations are built with 42 concrete beams $59.1 \times 14 \mathrm{~cm}$ (modeled as structural beams), 66 elements masonry curb (done with the function structural walls) with a section of $14 \times 14 \mathrm{~cm}$, and a ground embankment as filling. Hinge boundaries that allow rotation are linked to the beams. The vertical structure is done with plenty of elements (bottom plates, pilasters, braces, noggings, and top plates) that have been made with structural columns, structural beams, and diagonal braces (Figure 14). 


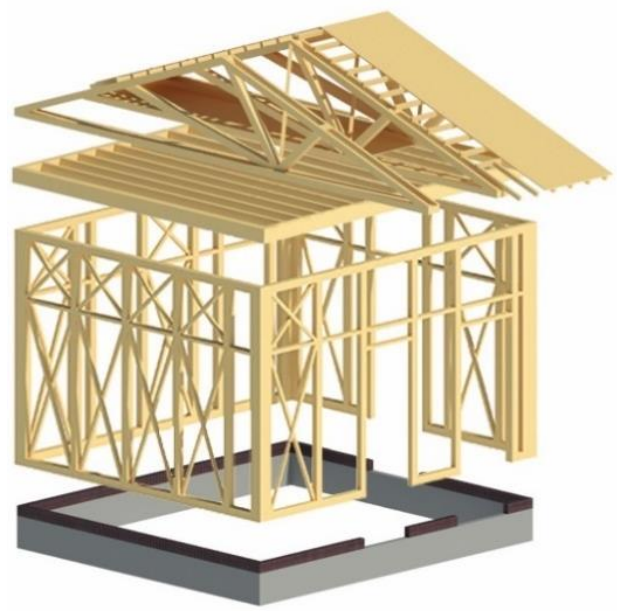

(a)

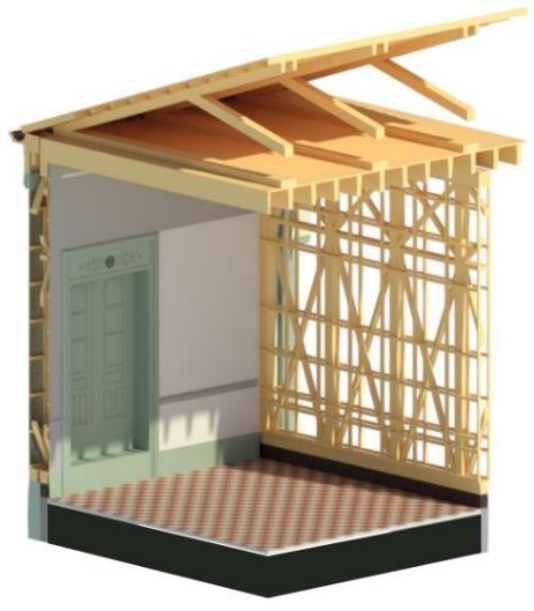

(b)

Figure 14. (a) Exploded and split axonometry of a structural section; (b) finishing details with supporting structures.

The hardest part was the design of a trussed roof (queen post geometry) with an inclined and diagonal king post. This is made of different levels of beam systems covered by wooden boardings. Beams and purlins are shaped as "structural beam" elements, creating a new family and changing the type; Trusses, instead, as "trusses", which is a more complex family that allows reading various elements correctly.

The secondary structure is divided into two different substructures, both without any analytical model, but allows the creation of architectonic and ornamental elements. The first one, functional to the external coating, helps to hold the sheets of metal deployer, characterized by a corrugated iron sheet finished with cement and plaster. The second one, on the other hand, is used for internal walls and to support the sheets of metal troquelade (Figure 15), and this has not got any brace.

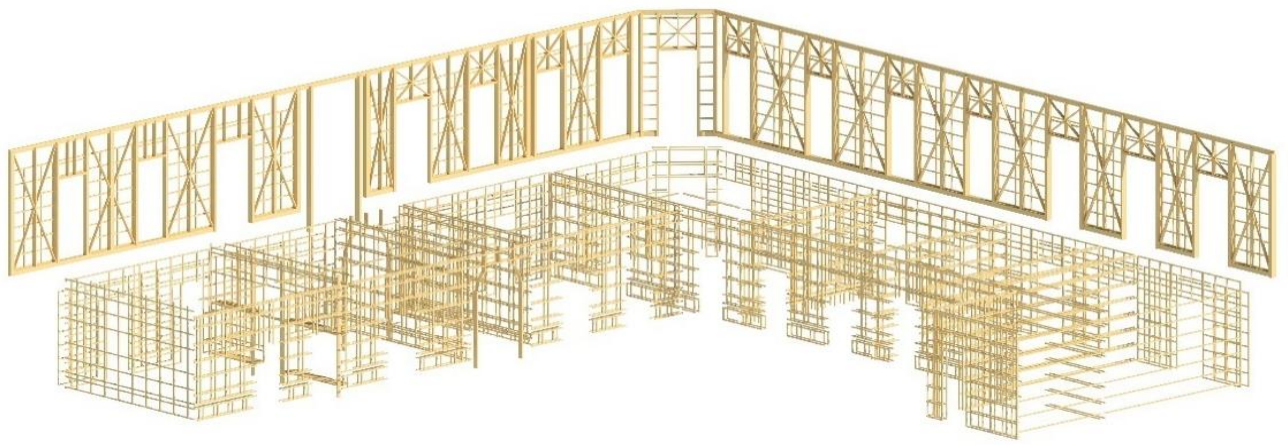

Figure 15. Secondary nonbearing structure to fix laminas internally and externally.

The original restored sheet metal is identified with marks that report the original name. Thanks to the function tag, filtered to the walls group, it is possible to visualize the correct place for each sheet shaped by the real location (Figure 16).

All the elements, except the masonry curb (plate element), are represented by a frame (beam element) with two nodes at the end.

The authors created a filter for the analytical model to diversify nodes: green nodes that connect two or more elements are auto-connected by the program need to use the function "analytics regulation"; blue nodes are manually moved through the above-mentioned function, and there could not be a precise match between analytical and geometric model; red nodes belong to bracket, and, for this reason, an edge is not connected (Figure 17). 


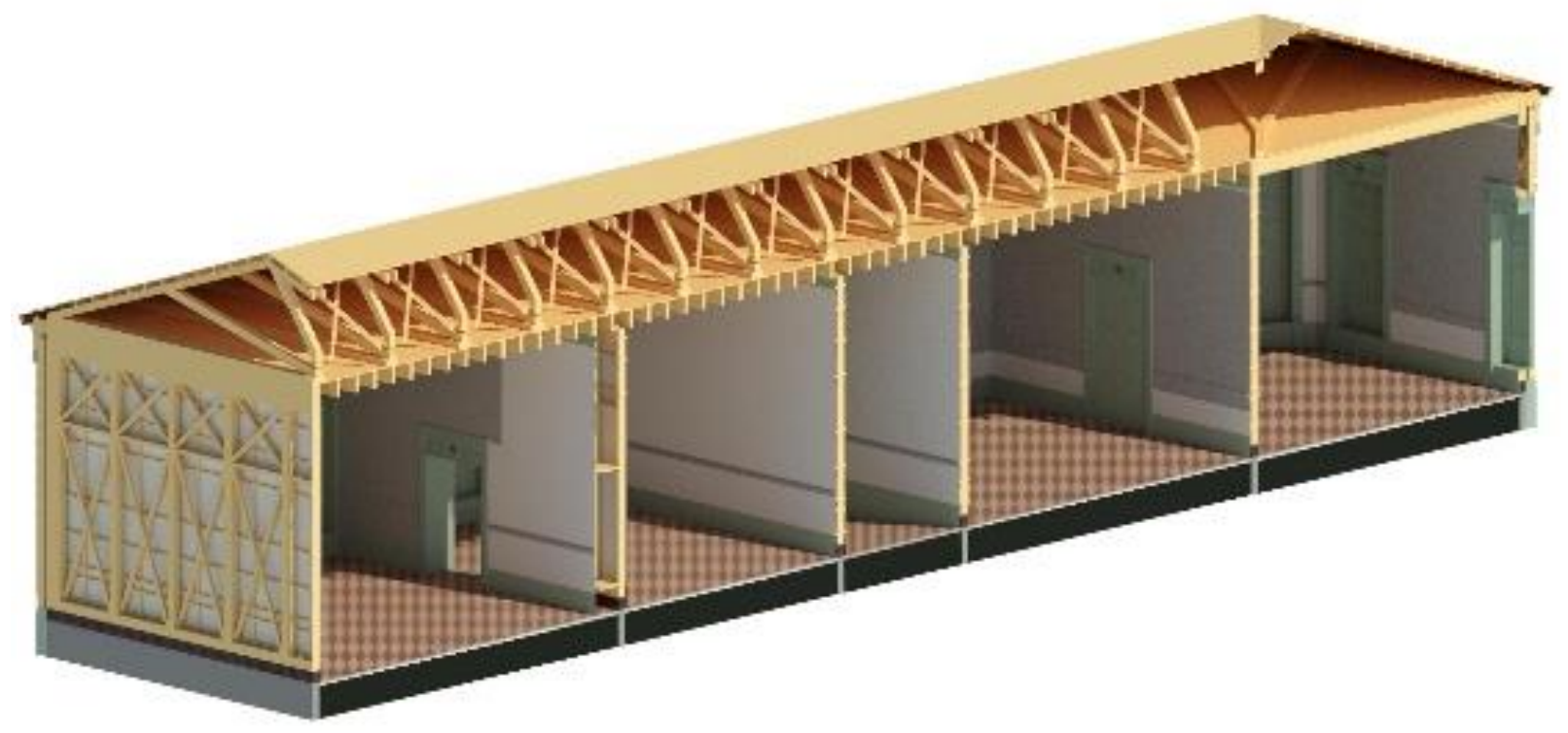

Figure 16. Architectonic section of Rey Prendes House.

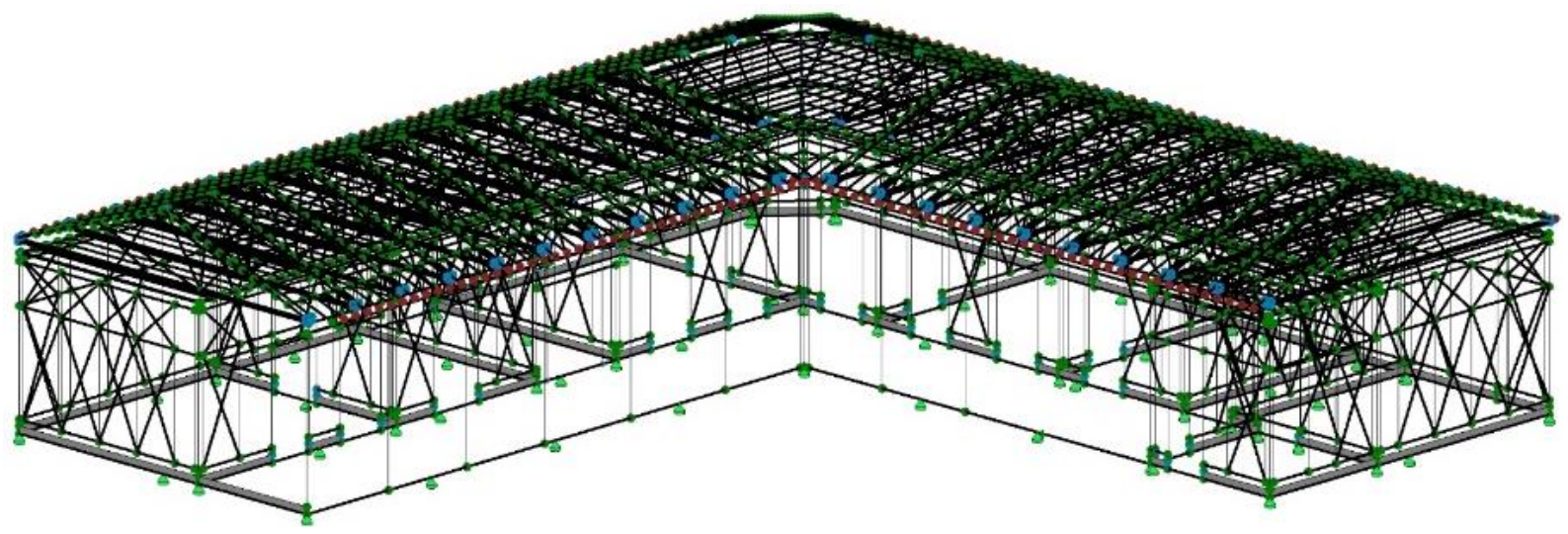

Figure 17. Analytical model of the project with filter (visualization properties).

This type of modeling by Revit provides limited evidence of the impossibility of creating new nodes on existing frames to divide them. Even if you try to create a new element as a new family and include the analytical model manually, this operation will fail. The frame for Revit cannot be divided in any way.

In a constructive system such as the balloon frame, where several systems of beams are overlapped to obtain a box behavior, it is difficult to auto-connect these frames in the middle of the geometry, layer after layer. For this reason, some layers are unable to be connected.

One way is to create a rigid link to connect them, but without dividing beams analytically, one single beam will be split into more elements, making computation mistakes in the abacus, or they can be connected later on MidasGen (Figure 18). As attested by the paper about structural design, there are also added loads (linear and hosted for wind).

All construction steps were controlled and verified with Autodesk Navisworks [21], with the aim to check interferences and overlap between frame elements finding and removing clash detections input. 


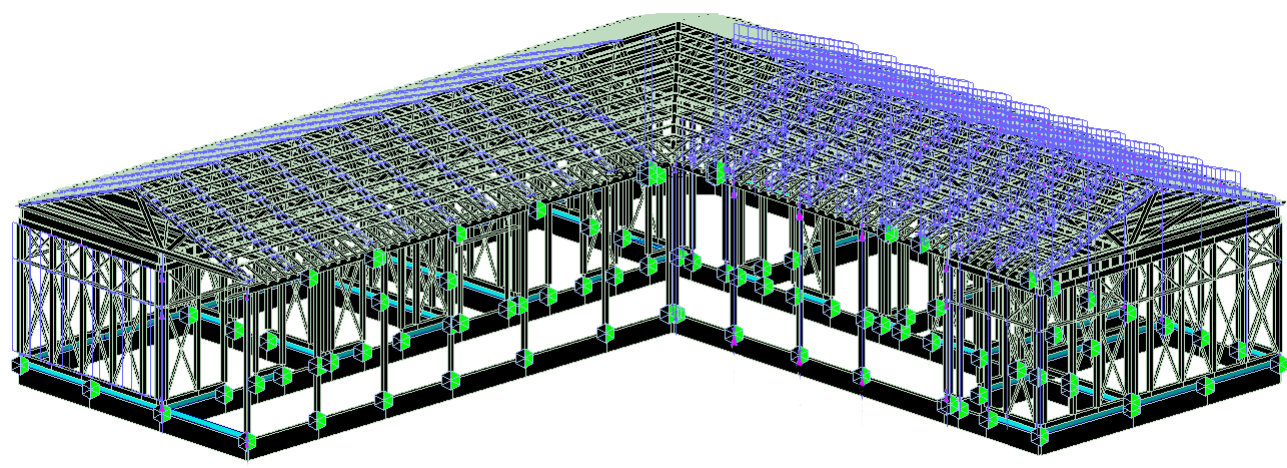

Figure 18. Analytical model read by MidasGen as imported with both materials and section properties as a result of BIM interoperability.

\section{Educational Construction Site: Setup and Activities}

In the state of El Salvador, a national policy for health and safety in the workplace was only adopted in 2006. Currently, the national guidelines in force in El Salvador provide for the drafting of a Prevention Plan which can be comparable to the Safety and Coordination Plan provided for in the Italian legislation (D.M. 81/08). The concept of risk assessment was formally shared internationally through the promulgation of the ISO 45001 standard "Management systems for occupational health and safety-Requirements and guidance for use". In Italy and the European Union, the legislation concerning health and safety in the workplace is now fully harmonized.

The project for the safety of the construction site of the Rey Prendes House in the Municipality of San Salvador was designed to integrate the planned philological restoration and enhancement project. The main aim of this peculiar project was to facilitate the restoration work through the efficient management of health and safety during the construction site. The safety project was carried out taking into account the peculiarities of the following phases:

- Identification, description of the work, and analysis of the context;

- Identification of the materials and technologies used for construction;

- Organization of the construction site;

- Coordination methods and prescriptions for the management of health and safety on the construction site.

In order to obtain these goals, collective insurance was taken out and PPE (personal protective equipment) was provided due to cover the majority of accidental personal injuries.

The execution of all these different phases was characterized by the component of learning by doing with the support of the Roma Tre University (as the execution authority) to provide technical assistance with the hiring of national human resources (academic staff from UE or other countries).

This whole system is thought of as a specialized organization that works to develop the evolution of a new pedagogical way to interpret and combine theoretical $(40 \%)$ and practical $(60 \%)$ lessons for the realization of a working educational construction site.

The aim is to guarantee technical skills transmission through professional training (joinery, carpentry, and others).

Following the educational program of Escuela Artes y oficios tradicionales, it was necessary to develop several skills for the construction and building sector which took place over a year. As a matter of fact, the restoration of the Rey Prendes House as a didactic workshop took about 12 months, was carried out in conjunction with the technical structures of the Government of San Salvador, with the participation of the Vice-Ministry of Housing and Urban Development. 
So, the educational activity was divided into four different phases:

- Transmission of general culture of heritage;

- Transmission of theoretical-practical competencies to form skilled labor;

- Restoration and conservation works;

- Certification and promotion in the job market.

Each step of the process must satisfy the needs of a historical building, guaranteeing the survival of traditional crafts, especially with the increasing demand in San Salvador.

The Rey Prendes House is located in a quadrangular urban block with two sides facing two driveways perpendicular to each other.

The house is built around the perimeter of the area and has an internal courtyard. In order to avoid the progressive deterioration of the house, a temporary metal roof was placed on pillars.

The entire area of the building was fenced off and the only entrance was allowed through the main door. So, nowadays there is only one viable access from the south for the workers.

The construction site involved the whole building simultaneously.

The area inside the courtyard was divided into two distinct parts: a storage area for materials and one for the positioning of the worktops for the restoration of the walls (Figure 19).

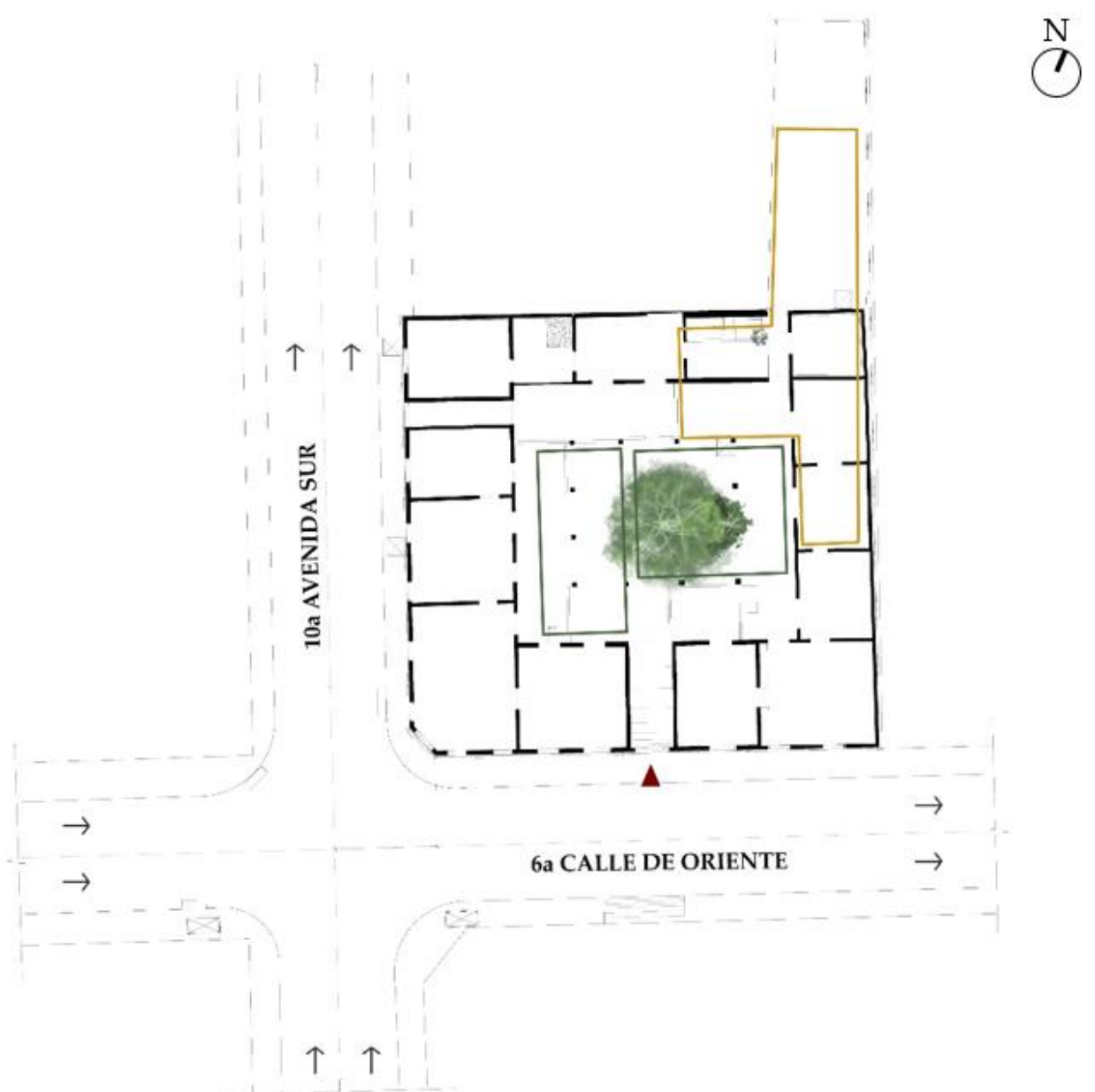

Figure 19. Construction site layout with the main entrance in red, the storage area in green, and the area for the restoration of the laminas in yellow. 
The first actions to follow for the opening of the construction site were:

- Disassembly of the infill structures and verification of the state of deterioration;

- Positioning of decorative devices on the work surfaces;

- On-site restoration of panels.

Then a fixed metal scaffolding was installed both in the internal part of the building and in the external one.

A timely and detailed risk assessment was carried out for each of these phases, to guarantee protection for all workers, and for future visitors, who will use the spaces of the "Rey Prendes House".

Two hundred students and adults were trained in the restoration of historic buildings through a course of 47 weeks and a total number of 1645 h (classroom: 150 h; practical workshop: 1495).

Cooperatives were created to promote the insertion of young people into the world of work.

Both awareness and dissemination campaigns were done, among the network of public schools in the country through MINED, through the preparation of physical, digital, and audiovisual material for the valorization and promotion of cultural heritage in general.

Hiring students means combating organized youth crime and, at the same time, producing beneficial effects for the defense of cultural heritage.

The activity is documented in the following photos, which show the construction site and workshop moments (from Figures 20-24).

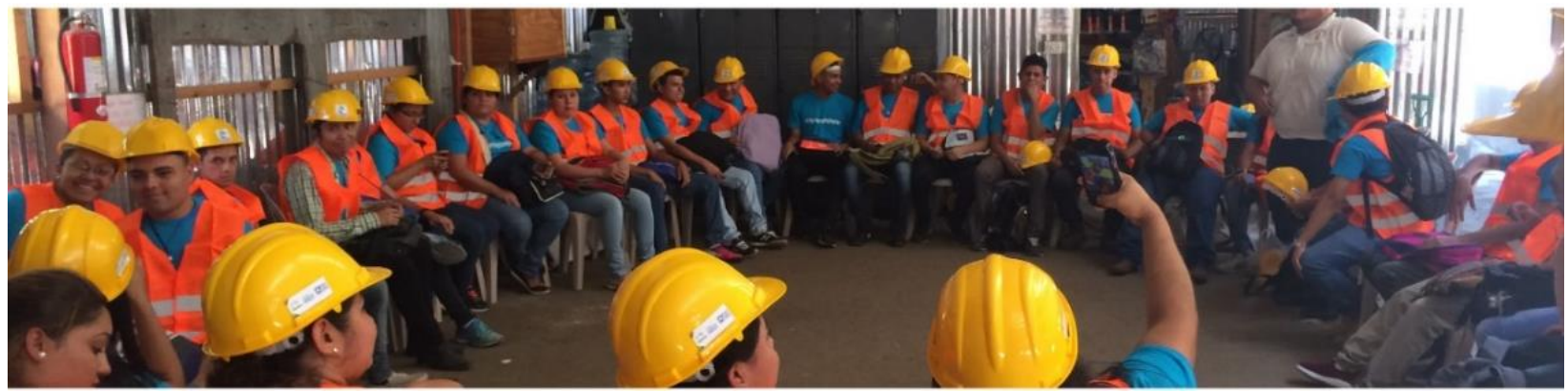

Figure 20. Workshop session with students and workers.

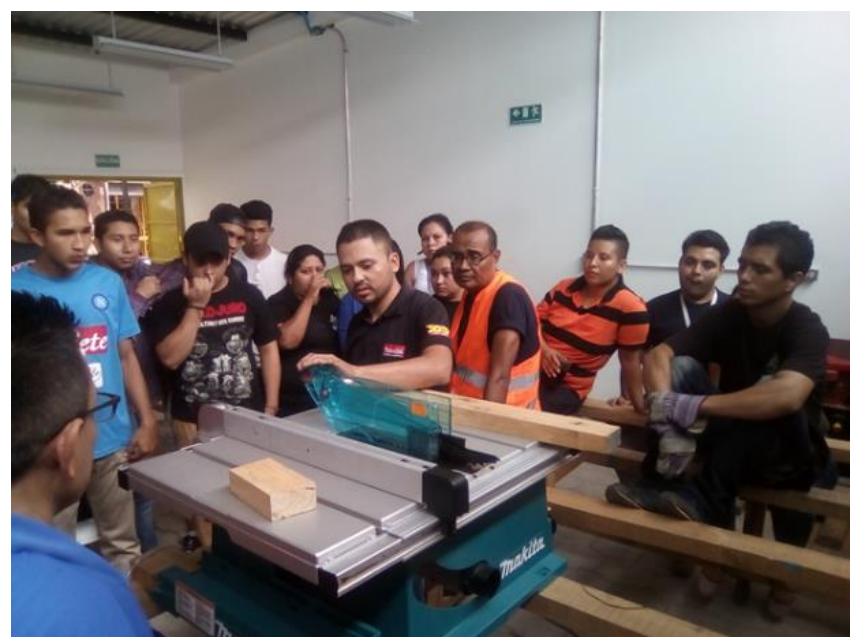

(a)

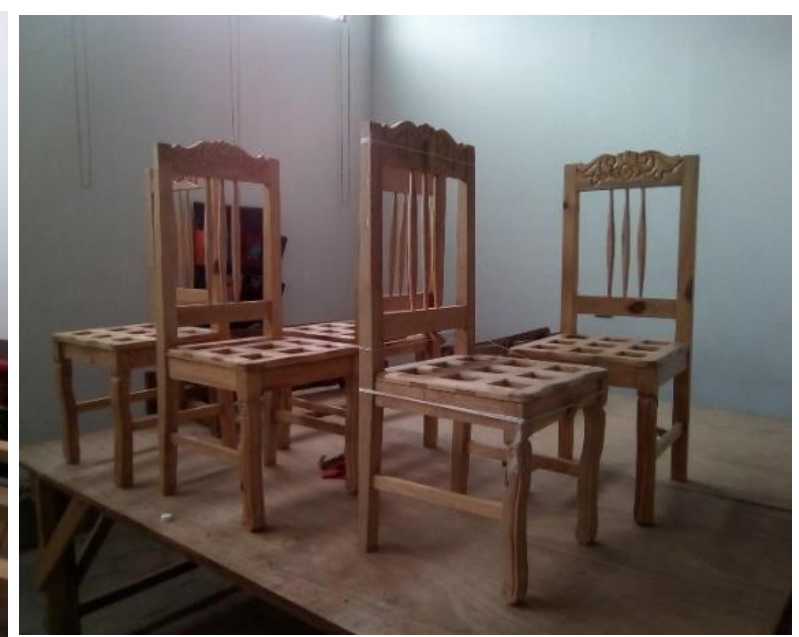

(b)

Figure 21. (a) Joinery and woodworking lessons for wood furniture; (b) final products made by students and other workshop participants. 


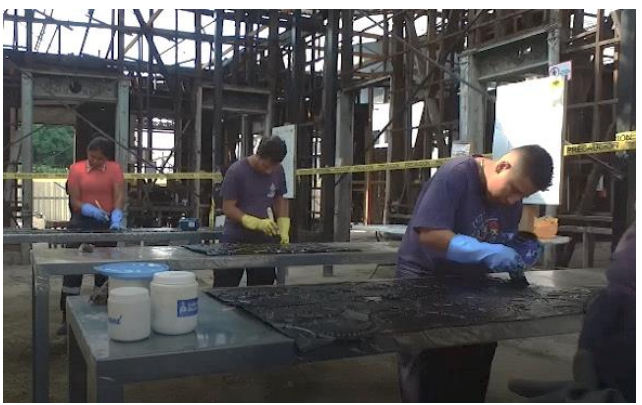

(a)

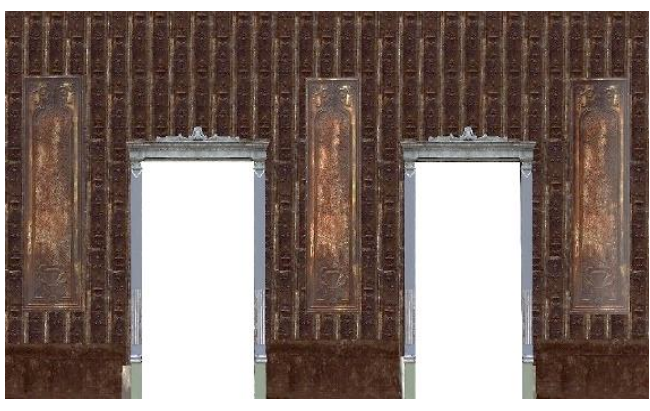

(b)

Figure 22. (a) Laboratory of the construction site for the workshop for sheets metal restoration; (b) Laminas' relief before restoration on site.

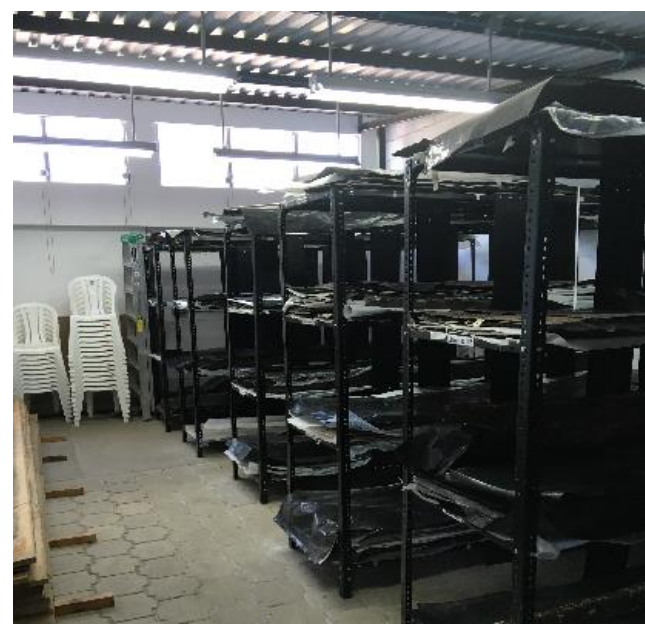

(a)

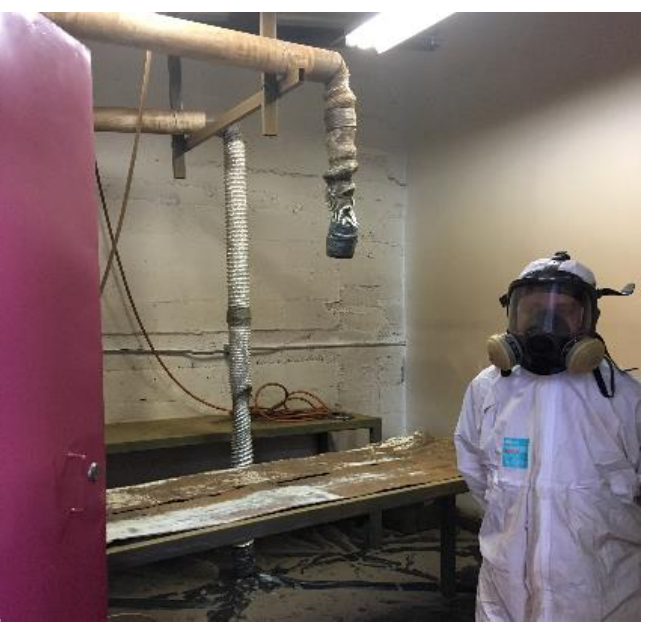

(b)

Figure 23. (a) The laboratory for the treatment of laminas and the archive; (b) Restoration laboratory of sheets metal.

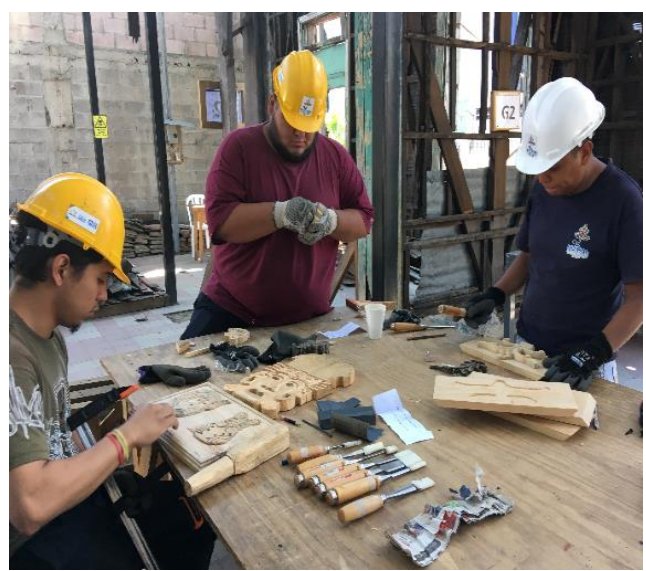

(a)

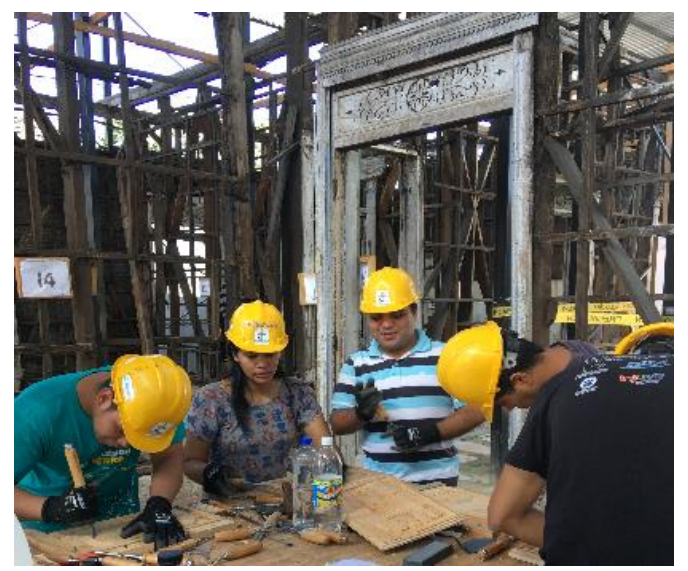

(b)

Figure 24. $(\mathbf{a}, \mathbf{b})$ The realization of decorative elements.

With the BIM technology of the Revit model, it was possible to manage the entire process of the construction site, due to the interoperability of the file.

Using the Autodesk Naviswork, there was the possibility to organize the construction into three macro-phases, from the foundations to the rooftop, building the primary structure for each one, secondary structure, and finishing with details and decorations. 
Using this model, there was also the chance, to create a schedule, for the coordination of the construction site (Figure 25).

1. Foundations

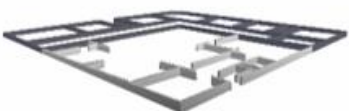

2. Elevation structure

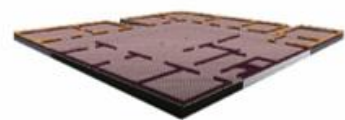

3. Finishing, laminas and roof

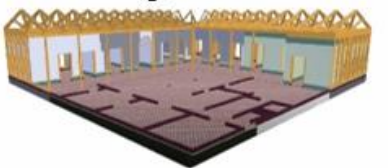

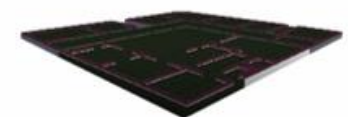
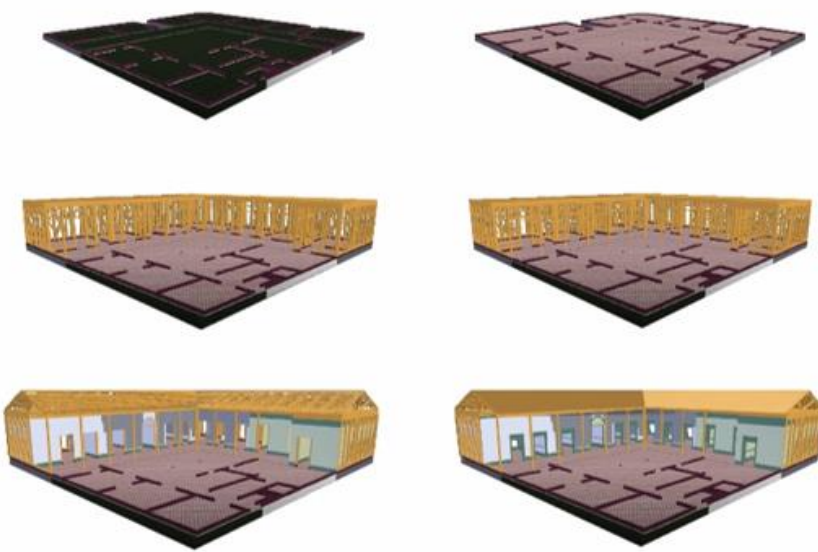

Figure 25. Construction site development thanks to BIM technology of Autodesk Revit.

\section{Conclusions}

The relationship with historic buildings is often difficult, complicated, and challenging; however, with complex and sophisticated methods it is possible to valorize existing heritage, monitoring and extending its whole life cycle [22].

The purpose of this research was to give an innovative and sustainable methodology for the approach to consolidation, restoration, or reconstruction of existing structures.

Due to this, the aim was to apply technology, usually used for new buildings, to program and organize an educational construction site. The target to be achieved, using the seven dimensions of the BIM technology (three of modeling, time, cost, management, and sustainability) [23], was to allow several future analyses, for which the model was already prepared (Figure 26).

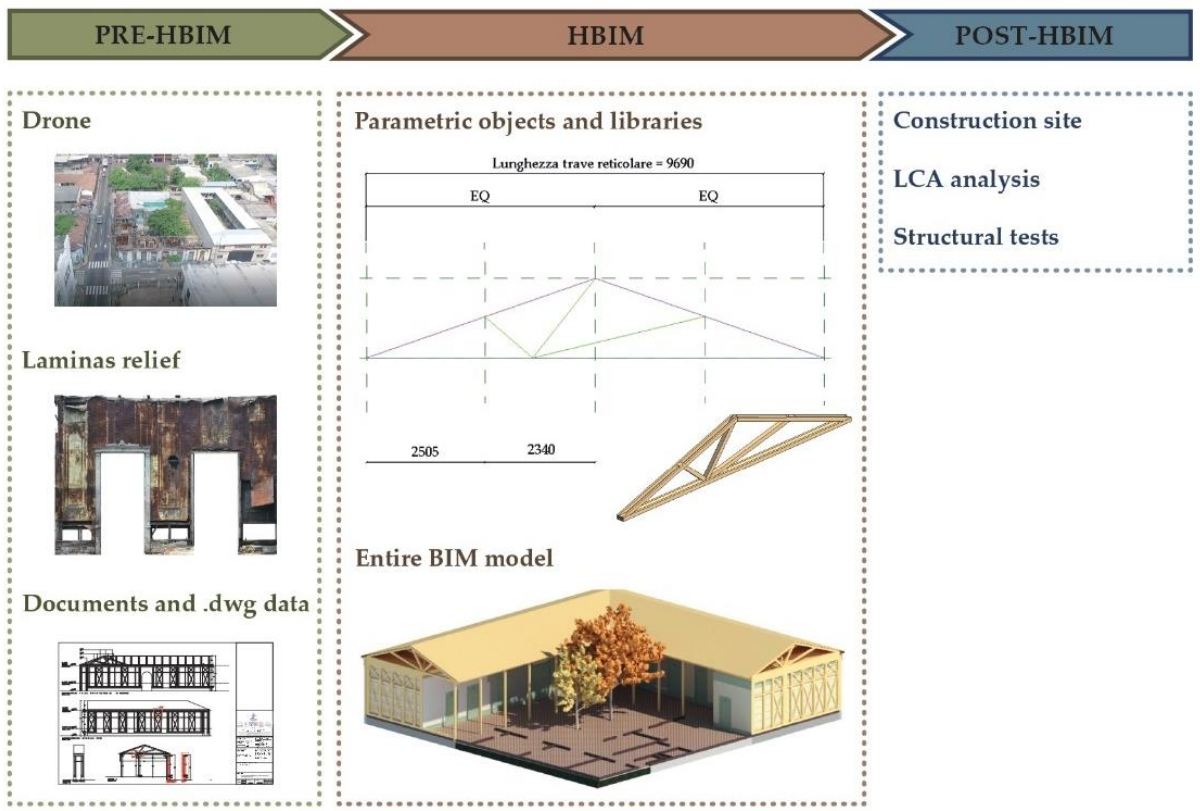

Figure 26. Summary of the HBIM process used for this case study.

Following the example of previous papers, as in the case of the Cloister of the San Telmo Museum by Iñigo Leon et al. in 2020, a model was totally constructed with BIM 
technology from laser scanning and point clouds documents [24]. The authors focused their interest on the chance of linking more functions, especially related to structural testing.

The aim was to connect the traditional way of relief for restoration and conservation, with the most innovative and sustainable techniques of implementing testing data and material properties.

The addition of the educational construction site provided a never-used aspect of sustainability and the social issue solution, which could be used more often in the future to bring the population closer to its historical heritage.

The work done with the BIM technology, from the historic research and the geometric survey to the definition of the digital twin, allowed a sustainable organization of a collective educational construction site, for the restoration of the structures, construction details, and materials, with the aim to preserve the architectural heritage [25].

This case study, of the future national coffee museum, represents a model for a new digital approach that could be used for several buildings, such as the Rey Prendes House, to preserve the heritage of the so-called San Salvador CHSS (Centro Historico de San Salvador).

From now on, it will be possible to unify restoration with construction site organization thanks to BIM modeling. Using this technology it is possible to study the most cost-effective solution in terms of both money and sustainability, organizing a construction site, without ever losing sight of the big picture.

The processing iter follows a sequence of linear and logical passages, characterized by the control of sustainability: starting with the data and information collection, it focuses on the creation of a three-dimensional and virtual library, that is accessible and editable by all the involved specialists [26]. The setting of named and defined parametric object, allows the check of materials through the abacus [27].

The use of this technology is not only useful for the construction site organization but also to involve the citizens in a sustainable process of restoration, generating, and growing a collective awareness, and passing on a traditional and fundamental construction technique for the culture of a Country.

Author Contributions: BIM processing, V.B.; data acquisition and worksite school processing, E.O.P.; project administration and funding acquisition, M.M.; scientific director of the work, conceptualization, and editing of the paper, S.S.; all authors have contributed to the writing and reviewing. All authors have read and agreed to the published version of the manuscript.

Funding: This research was partially funded by the Italian Agency for Cooperation for Development through the project Fortalecimiento de la Secretaría de Cultura de la Presidencia de El Salvador a través de la valorización del patrimonio cultural. AID 9961.

Data Availability Statement: The data presented in this study are available on request from the corresponding author.

Acknowledgments: The authors want to thank Ayansi Avendaño for the historical data of the House. A sincere thanks also go to the worksite-school teachers and students for their passion and strong collaboration.

Conflicts of Interest: The authors declare no conflict of interest.

\section{References}

1. Bommer, J.J.; Salazar, W.; Samayoa, R. Riesgo Sísmico en la Región Metropolitana de San Salvador; PRISMA: San Salvador, El Salvador, 1998; 78p.

2. Bommer, J.J.; Benito, M.B.; Ciudad-Real, M.; Lemoine, A.; López-Menjívar, M.A.; Madariaga, R.; Mankelow, J. The El Salvador Earthquakes of January and February 2001: Context, Characteristics and Implications for Seismic Risk. Soil Dyn. Earthq. Eng. 2002, 22, 389-418. [CrossRef]

3. Ministerio de Medio Ambiente: Dirección General de Observatorio de Amenazas y Recursos Naturales. Available online: Www.snet.gob.sv/ver/ (accessed on 9 December 2021).

4. PRISMA: Plan de Desarrollo Territorial Para la Subregión Metropolitana de San Salvador. Available online: www.prisma.org.sv / (accessed on 9 December 2021). 
5. Megahed, N. Towards a Theoretical Framework for HBIM Approach in Historic Preservation and Management. Int. J. Res. 2015, 3, 130. [CrossRef]

6. Murphy, M.; McGovern, E.; Pavia, S. Historic Building Information Modeling-Adding Intelligence to Laser and Image Based Surveys of European Classical Architecture. ISPRS J. 2013, 76, 89-102.

7. Murphy, M.; Corns, A.; Cahill, J.; Eliashvili, K.; Chenau, A.; Pybus, C.; Shaw, R.; Devlin, G.; Deevy, A.; Truong-Hong, L. Developing Historic Building Information Modeling guidelines and procedures for architectural heritage in Ireland. Int. Arch. Photogramm. Remote Sens. Spat. Inf. Sci. 2017, XLII-2/W5, 539-546. [CrossRef]

8. Oreni, D.; Brumana, R.; Georgopoulos, A.; Cuca, B. HBIM for conservation and management of built heritage: Towards a library of vaults and wooden bean floors. ISPRS Ann. 2013, II-5/W1, 215-221. [CrossRef]

9. Di Giuda, G.M.; Villa, V.; Piantanida, P. BIM and Energy Efficient Retrofitting in School Buildings. Energy Procedia 2015, 78, 1045-1050. [CrossRef]

10. Lu, K.; Jiang, X.; Yu, J.; Tam, V.W.Y.; Skitmore, M. Integration of life cycle assessment and life cycle cost using building information modeling: A critical review. J. Clean. Prod. 2021, 285, 125438. [CrossRef]

11. United Nations: Sustainable Development Goals. Available online: https://www.un.org/sustainabledevelopment/developmentagenda/ (accessed on 29 December 2021).

12. Kloepffer, W. Life Cycle Sustainability Assessment of Products. Int. J. Life Cycle Assess. 2008, 13, 89-95. [CrossRef]

13. Gigliarelli, E.; Calcerano, F.; Cessari, L. Heritage Bim, Numerical Simulation and Decision Support Systems: An Integrated Approach for Historical Buildings Retrofit. Energy Procedia 2017, 133, 135-144. [CrossRef]

14. Barazzetti, L.; Banfi, F.; Brumana, R.; Gusmeroli, G.; Previtali, M.; Schiantarelli, G. Cloud-to-BIM-to-FEM: Structural Simulation with Accurate Historic BIM from Laser Scans. Simul. Modeling Pract. Theory 2015, 57, 71-87. [CrossRef]

15. Murphy, M.; McGovern, E.; Pavia, S. Historic building information modeling (HBIM). Struct. Surv. 2009, 27, 311-327. [CrossRef]

16. Abdelmohsen, S.; Kamel, S. Heritage Building Information Modeling: Towards a New Era of Interoperability. In Architecture and Urbanism: A Smart Outlook; Springer: Cham, Switzerland, 2020; pp. 231-239.

17. SAP2000; version 2021; Computers and Structures Inc.: Berkeley, CA, USA, 2021. Available online: www.csi-italia.eu (accessed on 9 December 2021).

18. Revit; version 2021; Autodesk: San Rafael, CA, USA, 2021. Available online: www.autodesk.com (accessed on 9 December 2021).

19. Autocad; version 2021; Autodesk: San Rafael, CA, USA, 2021. Available online: www.autodesk.com (accessed on 9 December 2021).

20. MidasGen; version 2021; Cspfea: Este, Italy, 2021. Available online: www.cspfea.net (accessed on 9 December 2021).

21. Naviswork; version 2021; Autodesk: San Rafael, CA, USA, 2021. Available online: www.autodesk.com (accessed on 9 December 2021).

22. Stober, D.; Žarni'c, R.; Penava, D.; Turkalj Podmanicki, M.; Virgej-Đuraševi 'c, R. Application of HBIM as a Research Tool for Historical Building Assessment. Civ. Eng. J. 2018, 4, 1565. [CrossRef]

23. Reinoso-Gordo, J.F.; Rodríguez-Moreno, C.; Gómez-Blanco, A.J.; León-Robles, C. Cultural Heritage conservation and sustainability based on surveying and modeling: The case of the 14th century building Corral del Carbón (Granada, Spain). Sustainability 2018, 10, 1370. [CrossRef]

24. Leon, I.; Pérez, J.J.; Senderos, M. Advanced Techniques for Fast and Accurate Heritage Digitisation in Multiple Case Studies Sustainability 2020, 12, 6068. [CrossRef]

25. Bruno, S.; De Fino, M.; Fatiguso, F. Historic Building Information Modelling: Performance assessment for diagnosis-aided information modelling and management. Autom. Constr. 2018, 86, 256-276. [CrossRef]

26. Acierno, M.; Cursi, S.; Simeone, D.; Fiorani, D. Architectural heritage knowledge modelling: An ontology-based framework for conservation process. J. Cult. Herit. 2017, 24, 124-133. [CrossRef]

27. Bruno, N.; Roncella, R. HBIM for Conservation: A New Proposal for Information Modeling. Remote Sens. $2019,11,1751$. [CrossRef] 